\title{
Actuación arqueológica subacuática en los bajos al noroeste de la ciudad de Cádiz
}

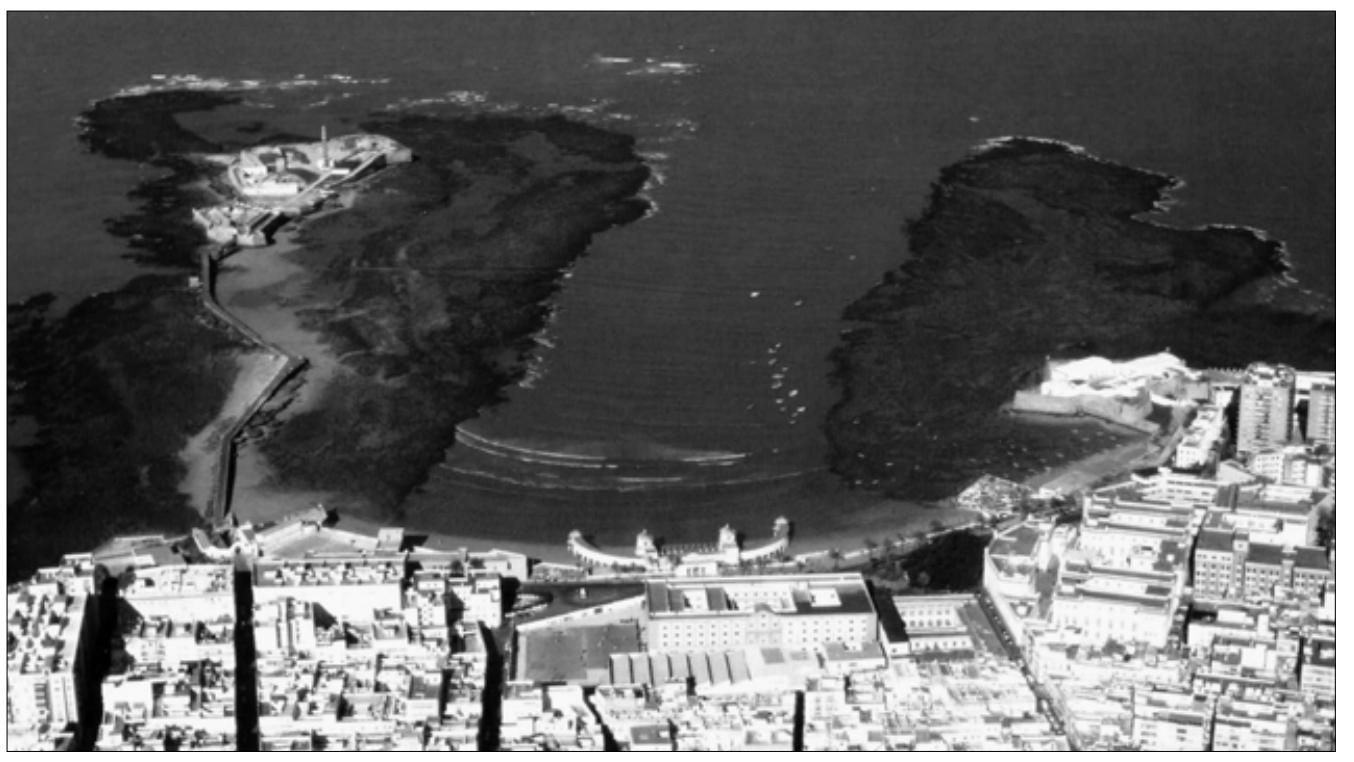

I. Vista aérea de la zona de trabajo.

Nuria Rodríguez Mariscal Josefa Martí Solano

Centro de Arqueología Subacuática. IAPH

Resumen

Con objeto de favorecer la tutela del patrimonio arqueológico sumergido a través de acciones encaminadas a la investigación, protección, conservación, restauración y difusión, se puso marcha, desde el Departamento de Intervención del Centro de Arqueología Subacuática, una actuación arqueológica en una de las zonas más ricas de nuestro litoral. La elección de este área se estableció tomando como base el importante volumen de documentación, tanto bibliográfica como oral, que presuponía la existencia de posibles yacimientos.
Si bien es cierto que el área de La Caleta ha sido objeto de numerosos estudios parciales y de destacables hallazgos descontextualizados, era necesario abordar la zona con una visión de conjunto que permitiera obtener una constatación y valoración de cada uno de los yacimientos, así como una normalización de los datos aportados por cada uno de ellos.

\section{Palabras clave}

Patrimonio Arqueológico Subacuático / La Caleta / Cádiz / Yacimientos Subacuáticos / Base de Datos Arqueos

\section{Introducción}

El papel desempeñado a lo largo de la Historia por la bahía gaditana ha estado, en todo momento, estrecha- 


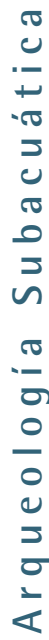

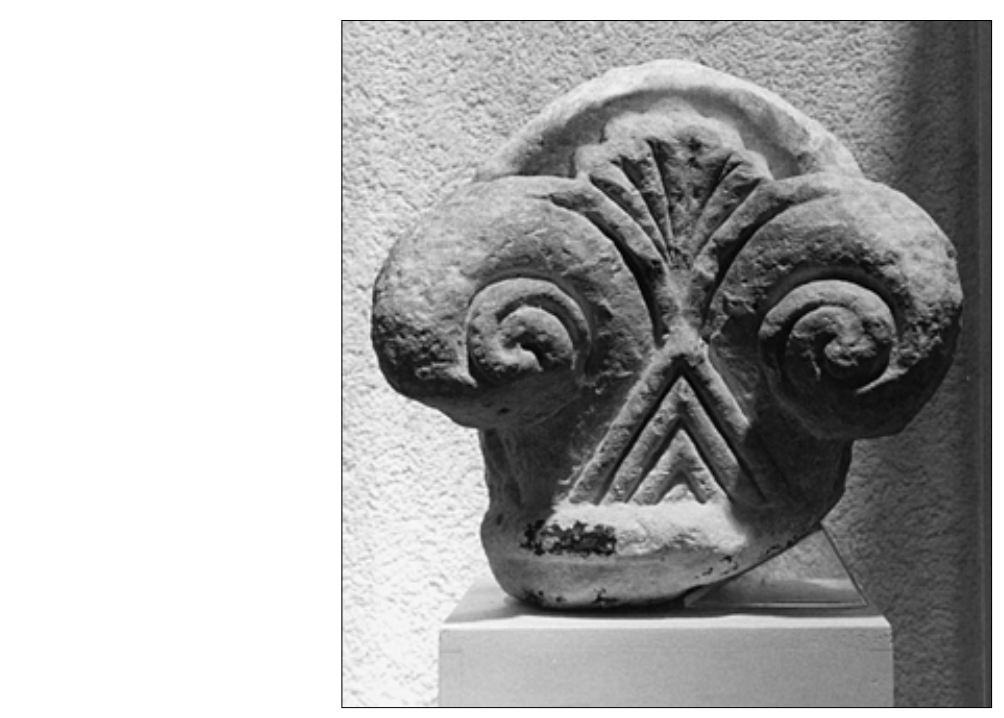

2. Capitel protojónico procedente de La Caleta. Museo de

Cádiz.

3. Thymaterium. Museo de Cádiz. mente vinculado a los condicionantes físicos que la caracterizan. La propia evolución de su configuración a partir de un núcleo de islas, los ríos que desembocan en sus inmediaciones, su situación estratégica en el ámbito del Estrecho junto con el marcado carácter de un paisaje volcado al mar ha influido, de manera decisiva, en el establecimiento de una sucesión de pueblos y culturas que participaron activamente en el desarrollo histórico del entorno de la bahía. Cádiz está ocupada en la actualidad por unos bajos rocosos que dificultan enormemente la navegación y que enmarcan una resguardada caleta (Foto I). Este área debió constituir un foco de atracción dentro de las limitaciones espaciales de la ciudad, tanto para el desarrollo de actividades relacionadas con el comercio, la pesca y el tráfico marítimo en general, como para la ubicación de lugares de culto. En este sentido, las referencias conocidas a través de los textos clásicos señalan la existencia de un Krónion dedicado a Baal Ammón y la edificación del Santuario de Venus Marina

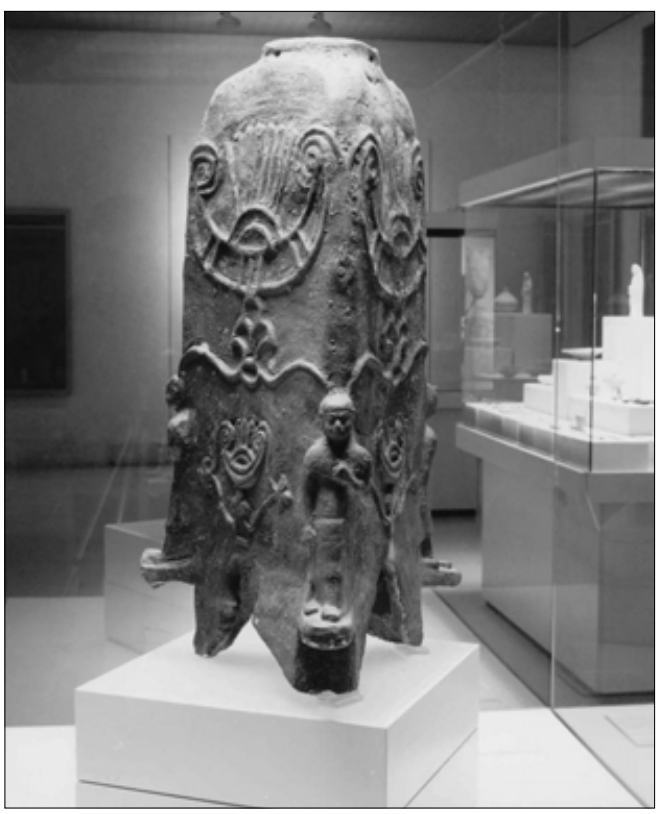

Dentro de este espacio natural, la zona noroeste de que describe Avieno en su Ora Marítima, situados ambos en las inmediaciones del Castillo de San Sebastián (Foto 2).

El devenir del tiempo y de las actividades del hombre ha dejado en estas aguas gran cantidad de restos materiales, convirtiendo la zona en un yacimiento arqueológico en su conjunto. La abundancia, variedad y calidad de los restos, junto con la facilidad de acceso por tratarse de una playa urbana, trajo consecuentemente un desarrollo desmesurado del expolio, constatado éste ya en el año | 884 con la extracción de un número indeterminado de ánforas en la Punta del Nao y continuándose hasta la actualidad cuando las condiciones de visibilidad lo permiten.

Como consecuencia directa de lo expuesto, este área ha sido objeto de estudio por parte de numerosos historiadores que desarrollaron diversas actuaciones arqueológicas desde los años setenta hasta los ochenta con resultados que no arrojaron una definición cultural clara de este entorno.

El Centro de Arqueología Subacuática, dentro de la programación de su Departamento de Intervención ha pretendido, con la puesta en marcha de esta actuación, continuar con los trabajos de inclusión de yacimientos arqueológicos del litoral de Andalucía en la Base de Datos Arqueos, herramienta de conocimiento imprescindible para poder llevar a cabo las labores de protección que la Consejería de Cultura le tiene encomendadas. Su ejecución ha servido de base para el planteamiento de estrategias futuras de conservación de los yacimientos arqueológicos sumergidos.

\section{Campaña 99/0I}

La importancia de la zona anteriormente descrita, unida al desconocimiento que tenemos de la misma, así como a la aparición de importantes hallazgos descontextualizados durante las últimas décadas (Foto 3), nos llevó a considerar imprescindible realizar una intervención arqueológica encaminada a cubrir los siguientes objetivos:

- Identificar y evaluar el patrimonio arqueológico subacuático susceptible de ser investigado con metodología arqueológica, procediendo a una correcta valoración y delimitación del mismo.

- Proponer, conforme a la Ley 1/91 de Patrimonio Arqueológico de Andalucía y el Decreto de Protección y Fomento las medidas de protección que se consideren adecuadas en cada caso reflejando, de acuerdo con la importancia o características de cada yacimiento, su integración en el Catálogo General del P.H.A. (como Zona Arqueológica, categoría específica o genérica).

- Diagnosticar las actuaciones que inciden sobre su conservación, identificando los principales factores de riesgo, adoptando las medidas preventivas necesarias 
para evitar o minimizar los posibles daños, actuando sobre las causas que provocan su degradación y proponiendo medidas concretas de conservación preventiva.

El objetivo general que se perseguía con la realización de esta intervención era el de favorecer la tutela del patrimonio arqueológico sumergido, entendida ésta, tal como se recoge en el "Plan General de Bienes Culturales 1996-2000", como el proceso integrado por diferentes acciones tendentes a su administración, investigación, protección, conservación, restauración y difusión. Ahora bien, la necesidad de establecer una correcta protección de estos bienes pasaba inevitablemente por tener un conocimiento global de los mismos.

Como consecuencia directa de lo expuesto, se estableció un área prioritaria de actuación tomando como referencia los datos obtenidos durante las labores de documentación desarrolladas previamente, tanto bibliográficos como orales, por los que se presuponía la existencia de posibles yacimientos.

La zona objeto de actuación se enmarcó dentro de un área que incluía principalmente el entorno de La Caleta y los Bajos situados al noroeste de la ciudad de Cádiz. Los yacimientos se seleccionaron a tenor de la información que habíamos obtenidos a través de las diferentes fuentes de información consultadas (Fig. I). Estos yacimientos, tras las labores arqueológicas realizadas, han sido agrupados en tres conjuntos diferentes (la numeración corresponde a la ubicación de cada yacimiento en el mapa):

\section{YACIMIENTOS ARQUEOLÓGICOS SUBACUÁTICOS DE} LOS BAJOS AL NOROESTE DE CÁDIZ

\begin{tabular}{ll}
\hline YACIMIENTOS CATALOGADOS & El Aculadero (10) \\
EN "ARQUEOS". PROPUESTAS & Bajos del Chapitel (18) \\
DE MODIFICACIÓN & $\begin{array}{l}\text { El Boucentaure I (2) } \\
\text { Punta del Nao (12) }\end{array}$ \\
\hline YACIMIENTOS NO INCLUIDOS & La Albujera (6) \\
EN "ARQUEOS". & El Boucentaure II (3) \\
PROPUESTA DE INCLUSIÓN & Cepo de Plomo (19) \\
& Pecio de la Sigillata (4) \\
& Piedras de Molino (9) \\
\hline POSIBLES YACIMIENTOS & Agrupación de Cañones (17) \\
SIN CONSTATACIÓN & Anclas del Bajo de La Olla (1) \\
ARQUEOLÓGICA & El Boucentaure III (16) \\
& Jabeque Árabe (8) \\
& Pecio Púnico del Canal de La \\
& Caleta(5) \\
& Pecio Romano del Canal del \\
& Sur (15) \\
& Pecio de las Dolias (13) \\
& Pecio de los Ladrillos (7) \\
Tambores de Columnas (11) \\
Zona de las Grandes Piedras \\
(14)
\end{tabular}

El sistema de trabajo desarrollado durante las actuaciones arqueológicas se basó en las prospecciones visuales y en los estudios batimétricos de la zona.

Para la prospección visual se adoptó en cada momento el método más adecuado según las condiciones existentes. En conjunto, las directrices que establecieron los métodos de búsqueda y prospección a utilizar en cada caso en particular fueron: número de buceadores de que se disponía, visibilidad de las aguas, características del fondo, corrientes y estado de la mar.

Teniendo en cuenta todos estos factores se optó por analizar las particularidades específicas de cada uno de los yacimientos con el objeto de aplicar el método que determinásemos fuera el más idóneo: buceador remolcado, búsqueda entre filières, reconocimiento siguiendo una filière, cuadrícula progresiva o búsqueda circular.

Una vez concluida la prospección superficial y realizado el tratamiento de toda la información obtenida en dicha fase, fue necesario proceder a un estudio más pormenorizado de determinadas zonas que, por sus características, requerían una mayor atención.

El sistema de trabajo a emplear en estos casos se basó en el reconocimiento visual mediante el método de círculos concéntricos que permitió, en un área de 25 ó 30 $m$ de radio, llevar a cabo una inspección total del terreno. Ello posibilitó la realización de planimetrías en las que quedó reflejada la topografía del fondo, la distribución de materiales y las características más relevantes de la zona.

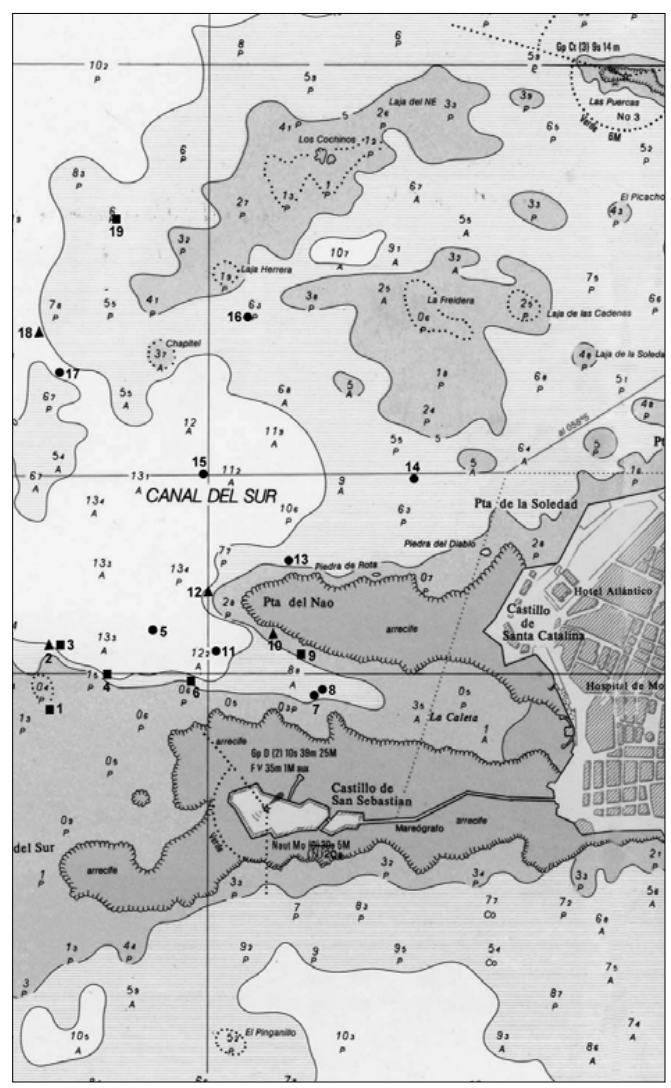

0
0
0
0
0
0
0
0
5
0
0
0
0
0
0
0
0
1

Figura I: Distribución de los yacimientos arqueológicos subacuáticos:

$\Delta$ Yacimientos arqueológicos subacuáticos catalogados en Base de Datos Arqueos

- Yacimientos arqueológicos subacuáticos por incluir en la Base de Datos Arqueos

- Posibles yacimientos arqueológicos sin constatación arqueológica 


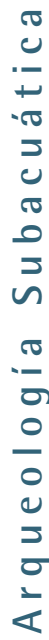

4. Trabajos de prospección en el yacimiento El Chapitel.

\section{Análisis de los yacimientos arqueológocos subacuáticos seleccionados}

Se ha considerado oportuno dividir en tres apartados independientes los distintos yacimientos estudiados según los resultados que se han obtenido de cada uno de ellos:

I. Yacimientos arqueológicos subacuáticos catalogados en la base de datos "ARQUEOS". Propuestas de modificación.

2. Yacimientos arqueológicos subacuáticos por incluir en la base de datos "ARQUEOS".

3. Posibles yacimientos subacuáticos sin constatación arqueológica.

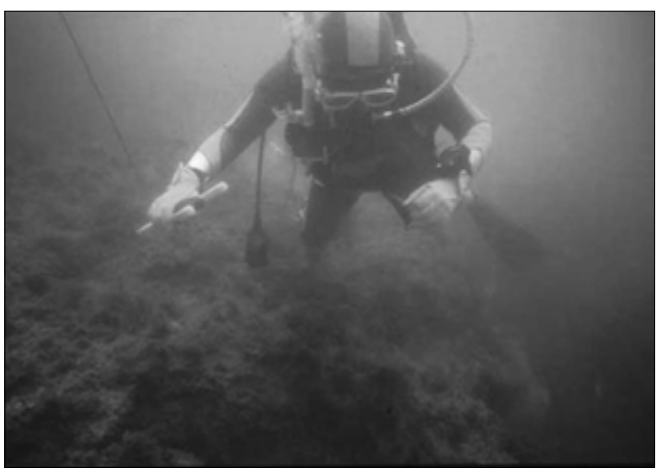

I. Yacimientos arqueológicos subacuáticos catalogados en base de datos "Arqueos". Propuesta de modificación.

En función de los datos obtenidos a lo largo de la actuación arqueológica se ha podido redactar una propuesta de modificación para aquellos yacimientos arqueológicos subacuáticos catalogados en la Base de Datos "Arqueos".

\section{El Aculadero}

La información oral recopilada apuntaba a la posible existencia de un pecio semienterrado con un cargamento anfórico de época romana que, en la década de los ochenta, aún conservaba parte de su maderamen.

Se iniciaron las prospecciones, tomando de referencia las indicaciones de antiguos buceadores de la zona, con el objeto de localizar el yacimiento en algún punto del recorrido a lo largo del cantil. Fueron numerosas las inmersiones realizadas en las inmediaciones. La falta de visibilidad característica en la zona dificultó las labores de reconocimiento durante toda la campaña, impidiendo desarrollar los trabajos proyectados para este yacimiento.

Aún así se pudo determinar, sobre un fondo marino de cascajo y piedra muy colmatado por el efecto de la dinámica litoral, la existencia de un conjunto de restos de cerámica de época púnica y romana dispersos en un área relativamente amplia, contrariamente a lo que esperábamos encontrar. Con respecto a la presencia del material de época púnica localizado, se baraja la posibilidad de que se encuentre desplazado de su lugar de origen a consecuencia de las corrientes marinas.

De ser cierta la información que se tenía acerca del yacimiento, éste debe hallarse actualmente bajo un cúmulo de aportes sedimentarios procedentes de la Bahía de Cádiz.

\section{Bajo del Chapitel}

Yacimiento definido por un conjunto de once cañones dispersos a lo largo de un laja de piedra en contacto con la arena. Gran cantidad de restos cerámicos de diversa cronología aparecen en torno de los cañones, donde se observan además diversos restos metálicos muy concrecionados.

La localización del yacimiento tuvo lugar en el transcurso de las campañas realizadas dentro del proyecto "Carta Arqueológica de la Bahía de Cádiz" (Foto 4). El objetivo de las inmersiones que se han llevado a cabo en la zona no ha sido otro que el determinar si las referencias orales que se tenían de otra agrupación de cañones cercanos a los del Chapitel, correspondían al mismo yacimiento. Finalmente se pudo comprobar que se trataba de los mismos cañones.

En el transcurso de las prospecciones se detectó la presencia de un cepo de plomo de uno dos metros de longitud.

\section{El Boucentaure I}

Se trata de los restos de un navío que la tradición oral relaciona con el barco francés Le Boucentaure, hundido en la Bahía de Cádiz tras la Batalla de Trafalgar. Sin embargo este dato aún está por constatar.

En campañas anteriormente realizadas por otros equipos de investigación se elaboró una planimetría de los restos que se encontraron en el fondo, a través de la cual se conoce parte de la estructura del navío. De entre los materiales registrados, destacar la presencia de algunos cañones de hierro, un ancla y otros objetos metálicos no identificados. Otra fuente de documentación consultada sobre este yacimiento aporta datos acerca de la existencia de parte de la quilla, algunas cuadernas y uno de los palos del barco, así como de unos de treinta cañones de hierro de algo más de dos metros de longitud.

A lo largo de la actuación arqueológica que se ha realizado desde el Centro de Arqueología Subacuática se ha intentado, en repetidas ocasiones, posicionar estos hallazgos. Siguiendo una cota de profundidad determinada, según las referencias que se tenían, se llevó a cabo una prospección circular de hasta 50 metros de radio con el fin de localizar los vestigios del naufragio. Sin obtener unos resultados positivos se continuó la búsqueda realizando líneas en paralelo a lo largo de los cantiles que limitan uno de los bajos rocosos de La Caleta, donde teóricamente se ubica el yacimiento.

Sin embargo, y debido a la colmatación que ha sufrido la zona en los últimos años, no fue posible determinar 
el emplazamiento exacto de los restos. Las referencias que se tenían del fondo marino para acceder al yacimiento han desaparecido bajo una espesa capa de fango y arena. Es probable que los restos se encuentren cubiertos por los sedimentos que la dinámica litoral ha ido depositado durante las últimas décadas.

\section{Punta del Nao}

Se habla de este yacimiento como si de una acumulación de pecios de distintas épocas se tratara, con materiales rituales de navegantes $\mathrm{o}$ arrojados desde el borde del cantil más próximo donde se presupone, por textos antiguos, la existencia de un templo.

Está considerada como un área de mucha dificultad para la navegación en condiciones adversas. Se trata de un yacimiento que, por sus características, presenta una gran complejidad a la hora de determinar su naturaleza tanto espacial como tipológicamente (Foto 5).

Se realizaron varias inmersiones de reconocimiento con el objeto de definir la ubicación exacta del yacimiento, una aproximación tipológica y cronológica de los restos arqueológicos así como obtener una delimitación de la extensión del yacimiento con respecto a la dispersión de los materiales localizados en superficie.

En el transcurso de las prospecciones se registró abundante material cerámico romano y púnico muy mezclado, así como piedras de molino y cantos rodados de gran tamaño que bien pudieran constituir el lastre de alguna embarcación. La zona, caracterizada por unos fondos de cascajos y enormes bloques de roca desprendidos del cantil, ha deparado desde antiguo gran cantidad de hallazgos arqueológicos (Foto 6).

Las malas condiciones de visibilidad impidieron delimitar la extensión del yacimiento, verificando la gran dificultad que presenta a la hora de determinar, como indicábamos anteriormente, la naturaleza compleja del mismo.

\section{Yacimientos arqueológicos subacuáticos por incluir en la base de datos "Arqueos".}

Del mismo modo, y como resultado directo de estos trabajos, se pudo localizar una serie de nuevos yacimientos arqueológicos. Los datos proporcionados por estos yacimientos se volcaron, conforme a las directrices marcadas por la Dirección General de Bienes Culturales, en la ficha normalizada, cumplimentada en modelo oficial, que sirve de base para su inclusión en la Base de Datos de Yacimientos Arqueológicos de Andalucía, herramienta imprescindible para ejercer las labores de tutela que la Administración tiene asignadas.

\section{La Albujera}

Las noticias que teníamos acerca de la existencia de este yacimiento provenían de informaciones orales que se habían recogido y que, aún siendo de distintos informantes, hacían alusión a los mismos datos.

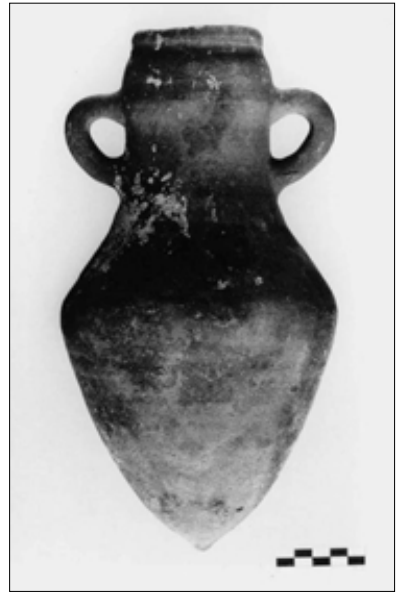

5. Ánfora púnica de pequeñas dimensiones hallada en aguas de La Caleta. Museo de Cádiz.

6. Conjunto anfórico extraído de la Punta del Nao. Fotografía de García y Bellido. Año |96|.

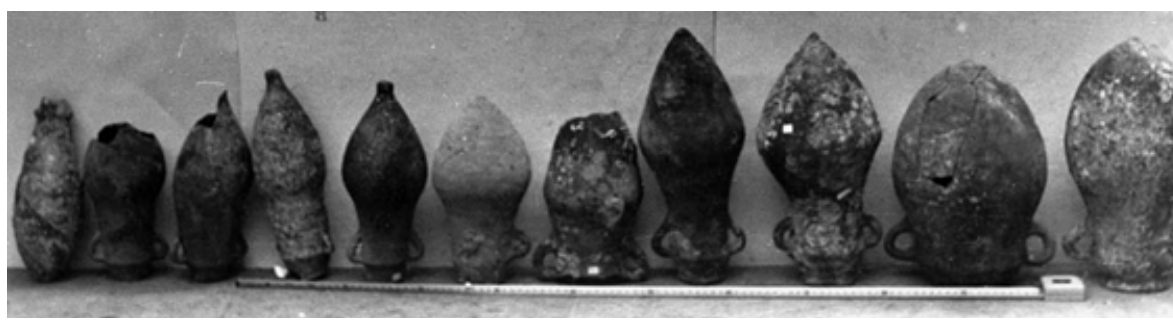

Se trata de una zona donde las gentes acudían con bajamar, ya en 1975, a extraer ánforas del tipo Dressel 20 que quedaban en superficie sobre el cantil interno de uno de los bajos de La Caleta. Siguiendo la misma línea, pero al pie del cantil, se describe otra agrupación de ánforas del tipo Dressel 8 que pudieran tener conexión con las halladas en superficie.

Se inician los trabajos arqueológicos revisando la zona y localizando una acumulación significativa de material cerámico de época romana de proporciones medias: ánforas fragmentadas, restos de ollas y anclas de piedra. Se verificó, por medio de prospecciones con picas, que bajo los fondos de arena que caracterizan la zona se ocultan restos arqueológicos enterrados.

\section{El Boucentaure II}

Un buceador de la zona se ofreció a acompañarnos a este yacimiento del que no teníamos documentación previa. Tras una inmersión de reconocimiento se localiza un ancla, del tipo almirantazgo, un conjunto de ocho cañones y material metálico no identificado. Los restos se encuentran relativamente disperso en una zona muy próxima al yacimiento denominado Le Boucentaure I. Se posicionó el yacimiento, delimitándose y realizando una planimetría del conjunto de restos arqueológicos (Fig. 2).

En desarrollo del proyecto "Conservación in situ de grandes objetos metálicos", puesto en marcha por el Departamento de Conservación del Centro de Arqueología Subacuática, el equipo de especializado en este campo realizó distintas inmersiones con el objeto de inspeccionar el grado de deterioro de los cañones y desconcrecionar zonas puntuales de los mismos en busca de marcas de identificación. 


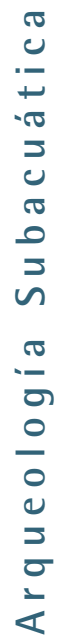

Figura 2: Planimetría del yacimiento El Boucentaure II.

Actualmente el yacimiento se encuentra en un proceso de análisis con la intención de confirmar si los restos localizados pudieran corresponder al citado navío francés Le Boucentaure.

\section{Cepo de Plomo}

Próximo al Bajo del Chapitel, y en el transcurso de una prospección cuyo objetivo era la localización de otro yacimiento, se encontró de manera fortuita un cepo de plomo de unos dos metros de longitud. El cepo no se hallaba, desde una primera aproximación, asociado a otros restos arqueológicos. Se consideró, pues, que se trataba de un hallazgo aislado.

\section{Pecio de la Sigillata}

Sobre un fondo rocoso se descubrieron, en muy buen estado de conservación, dos piezas de sigillata estampilladas semicompletas. El hallazgo tuvo lugar de forma casual, al intentar localizar los restos del denominado Boucentaure I. Las piezas fueron extraídas para proceder a su estudio y tratamiento de conservación y desalinización en los laboratorios del Departamento de Conservación del Centro de Arqueología Subacuática para su posterior depósito en el Museo de Cádiz. En la actualidad estas piezas forman ya parte de los fondos del Museo.

Se continuaron los trabajos de reconocimiento de la zona a través de prospecciones tanto circulares como lineales con intervalos cortos debido a la escasa visibilidad que había. En los alrededores, y muy dispersos, se detectaron restos anfóricos y pequeñas anclas de piedra.

Estos hallazgos pudieran pertenecer al cargamento de un navío de época romana, sin embargo esta hipótesis queda pendiente de confirmar.

\section{Piedras de Molino}

Yacimiento que se conoce a raíz de anteriores campañas arqueológicas desarrolladas en el entorno de La Caleta donde se hacía alusión a la existencia de piedras de molino, que son las que han dado nombre al yacimiento, así como de elementos de fondeo y bloques cuadrangulares. Este material podría proceder, con bastante probabilidad, de la extracción de elementos constructivos de la época en la que los Bajos de La Caleta se utilizaban como canteras para el suministro de las obras de construcción realizadas en la ciudad de Cádiz.

Durante los trabajos de reconocimiento que se llevaron a cabo se verificó la presencia de una serie de piedras circulares y semicirculares talladas de distinto diámetro, medio y pequeño, muy cercanas unas de otras, realizándose una planimetría de las mismas. En la zona aparecen fragmentos de bocas de anforiscos que probablemente no estén asociados a estos restos. Se han hallado, del mismo modo, tres piedras de molino de gran tamaño en las que la perforación central es evidente. Se prospectaron los alrededores con el fin de determinar la delimitación de esta agrupación de piedras.

La cronología de estos restos es indeterminada, pudiendo apuntar a época moderna y contemporánea en función de los fragmentos cerámicos que se localizan en el entorno y de las épocas de explotación de las canteras.

\section{Posibles yacimientos subacuáticos sin constata-} ción arqueológica

Por otra parte, los trabajos de documentación llevados a cabo han permitido recopilar un tipo de información de primera mano sobre otros posibles yacimientos subacuáticos aún sin constatación arqueológica. La confirmación de la existencia de estos yacimientos estaría sujeta a la realización de una segunda fase de intervención, ya que la falta de visibilidad, característica de la bahía gaditana, las corrientes de marea que se producen en la zona y las condiciones atmosféricas adversas que nos han acompañado durante gran parte de los trabajos, no posibilitaron el acceso y la constatación de los mismos.

El desarrollo de futuros trabajos arqueológicos en la zona permitirá que los datos aportados pasen a engrosar la Base de Datos Arqueos, cuando se confirme la existencias de nuevos yacimientos, o a una base de datos paralela donde quedan registradas aquellas informaciones que no pudieron ser contrastadas en el transcurso de las inmersiones realizadas.

El objetivo de la creación de la base de datos paralela no es otro que el de facilitar la acumulación y sistematización de una serie de documentación a la que recurrir en el caso de coincidencia con nuevas informaciones, o cuando las circunstancias meteorológicas (temporales que desplacen el cúmulo de sedimentos depositados sobre los yacimientos o vientos favorables que repercutan en la visibilidad de las aguas), hayan hecho variar las condiciones de la inmersión, haciendo posible la localización y evaluación de los yacimientos. 
Los yacimientos que se han tenido en cuenta a la hora de determinar su inclusión en la base de datos paralelala han sido aquellos que cumplían dos premisas previas: por una parte la fiabilidad de la fuente que aportaba la información, y por otra la coincidencia en un mismo yacimiento de fuentes de distinta procedencia. Los yacimientos que cumplen estas características son los siguientes:

\section{Agrupación de Cañones}

Los datos aportados por noticias orales hacen referencia a la existencia de una agrupación de ocho cañones de culatas muy anchas asociados a pastecas, restos de forro y maderamen de un navío.

La información sobre la existencia de conjuntos de cañones en aguas de la Bahía gaditana es muy amplia. Las noticias con referencias vagas sobre la localización de los mismos aumentan desmesuradamente el número de los posibles hallazgos Ante este hecho se necesita ir constatando cada uno de los datos que aportan pescadores y buceadores deportivos de la zona, para poder establecer el número de yacimientos reales y su asociación o no a un pecio. De hecho ha sucedido en alguna ocasión que varias informaciones que parecían corresponder a distintos yacimientos, con piezas de artillería como denominador común, resultaron ser al final el mismo emplazamiento.

\section{Anclas del Bajo de La Olla}

A través de los datos recopilados de varios buceadores de la zona, conocemos la posible existencia de dos anclas metálicas, una de ellas de gran tamaño, ubicadas en el Bajo de La Olla. Este bajo se sitúa en la zona central de la canal, con una profundidad que va desde los I 4 metros en la parte baja, hasta los 0.4 de la parte más alta contabilizada en la bajamar viva equinoccial.

La localización de las mismas podrá servir para poner estos hallazgos en relación o no con los restos de los pecios El Boucentaure I y II, muy cercanos espacialmente a las anclas, y con los que podría guardar relación. No descartamos la hipótesis de que la situación actual de estas anclas respondieran al resultado de maniobras extremas de fondeo ante el peligro de las embarcaciones a ser arrojadas con temporales a los bajos rocosos del Castillo de San Sebastián o de la Punta del Nao.

\section{El Boucentaure III}

Por fuentes documentales consultadas presumimos la existencia de los restos de un naufragio que podría pertenecer al anteriormente citado navío francés Le Boucentaure, hundido en la Bahía de Cádiz durante la Batalla de Trafalgar. Se describe este yacimiento como un pecio, compuesto por restos de maderamen, cañones de hierro y bronce, cureñas, pasadores de metal y numerosos restos de chapas metálicas que podrían corresponder a parte del forro del barco.

Desde el Centro de Arqueología Subacuática se está trabajando en la búsqueda de información a través de una documentación fotográfica antigua sobre piezas de artillería de bronce extraídas de este yacimiento. Se han mantenido contactos con el Departamente des Recherches Archeologiques Subaquatiques te Sous-marines, dependiente del Ministerio de Cultura y Comunicación francés, quienes han aportado una valiosísima información sobre las citadas piezas. El conjunto parece corresponder a la artillería de un buque de pabellón francés que se hundió con posterioridad a 1794, lo que no descarta en principio, la asociación tradicional de estos restos con el navío francés Le Boucentaure.

\section{Jabeque Árabe}

La información proporcionada por algunos buceadores de la zona, nos han aportado datos sobre la posible existencia, en la zona de La Caleta denominada Albujera Alta, de un jabeque árabe asociado a material cerámico vidriado. Algunos datos hacen referencia a un número indeterminado de platos vidriados en tonos azules y grafitados que se disponían apilados sobre el fondo.

\section{Pecio púnico del Canal de La Caleta}

Se describe este yacimiento como una concentración de material anfórico semienterrado y aparentemente en bastante buen estado de conservación. La cronología de los citados restos, por las referencias aportadas, correspondería a época púnica.

Se trata de un área relativamente amplia, con fondos de arena y fangos. El material se encuentra en una zona que queda con frecuencia cubierta de algas y restos vegetales, ya que están en una pequeña vaguada del fondo. En el transcurso de una inmersión de reconocimiento se localizó un ánfora tipo S-I I casi completa, prácticamente enterrada. En las labores de prospección de otro yacimiento cercano al anteriormente descrito se halló otra ánfora del tipo T-9.I.I.I también enterrada y en muy buen estado de conservación. Si formasen parte del mismo cargamento de un barco, la cronología apuntada por este material anfórico estaría entre el siglo $V$ y el III a.C., no descartándose la posibilidad de que se tratara de hallazgos independientes, sin relación aparente.

\section{Pecio romano del Canal del Sur}

Descrito por buceadores locales como un pecio de época romana con cargamento de ánforas. Tenemos constancia del expolio que ha sufrido el yacimiento en la última década. Por diversas fuentes sabemos que ha sido un lugar habitual de aprovisionamiento de ánforas para los expoliadores de la zona que negociaban su venta con compradores, la mayoría de ellos, de fuera de la ciudad de Cádiz.

\section{Pecio de las Dolias}

Los datos recopilados por las noticias orales consultadas, documentan la posible existencia de un pecio con cargamento de dolias, teniendo referencias de unos 5 ó 6 ejemplares, localizadas en las proximidades de la Punta del Nao.

\section{Pecio de los Ladrillos}

Yacimiento compuesto por ladrillos alineados y material constructivo variado. Se hicieron varias inmersiones de 
reconocimiento en el punto señalado por buceadores y pescadores de la zona, sin hallar ningún vestigio de los mismos. Probablemente, y de ser cierta su existencia, éstos se encuentren enterrados bajo la capa de sedimentos que cubre la zona. A través de la información recopilada se baraja la posibilidad de que se trate de un falucho con materiales de obra para alguna construcción en el cercano Castillo de San Sebastián.

\section{Tambores de Columnas}

Un informador describe una agrupación de tambores de columnas localizados en la parte central del canal de La Caleta. Se descarta que este yacimiento coincida con el denominado "Piedras de Molino".

\section{Zona de las Grandes Piedras}

Se trata de una zona cuyo fondo se caracteriza por la presencia de grandes bloques de piedra donde se concentra material cerámico entre las grietas. Se hicieron algunas inmersiones, pero la escasa visibilidad impidió su localización.

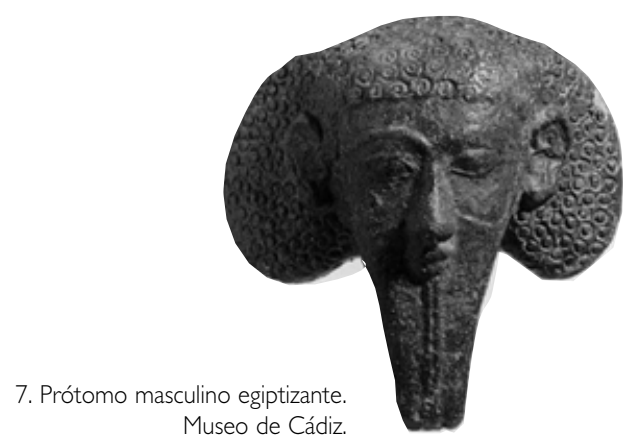

\section{Conclusiones}

Como ya hemos apuntado en el inicio del artículo, la importancia de este ámbito desde la perspectiva arqueológica es muy relevante, y creemos que puede catalogarse como una de las más ricas de Andalucía, no sólo por la abundancia de hallazgos y su valor desde un punto de vista histórico, sino también porque puede definir algunas incógnitas sobre las primeras sociedades que poblaron el territorio y sobre la actividad comercial que característico en cada momento histórico.

Para el estudio de esta zona es preciso tener en cuenta una serie de condicionantes físicos que incidirán, de manera decisiva, en el resultado que se pretende obtener.

Por una parte, y debido a su situación geográfica con respecto a la ciudad de Cádiz, estamos hablando de un área de ocio para la población. La playa de La Caleta es la única existente en el casco antiguo esta localidad. El acceso a los yacimientos se realiza desde la playa estando, la mayoría de ellos, a poca profundidad. Este hecho está directamente relacionado con el fenómeno del expolio que ha sufrido esta zona desde antiguo, siendo numerosas las noticias sobre objetos extraídos de sus aguas así como abundantes los registros de entrada de piezas en el Museo de Cádiz, sobre todo de material anfórico.
Otro factor que afecta al desarrollo de los trabajo es la escasa visibilidad con la que cuenta generalmente las aguas de la bahía gaditana, necesitándose unas condiciones mínimas para llevar a cabo la programación de las actividades arqueológicas, de ahí que las inmersiones puedan dilatarse mucho en el tiempo hasta tener unas condiciones mínimas que permitan rentabilizar la salida de los técnicos.

Podemos, sin embargo, considerar como factor positivo la proximidad espacial de las instalaciones del Centro de Arqueología Subacuática a la zona de estudio, lo cual a permitido aprovechar, para la práctica del buceo, los escasos días favorables ante los continuos temporales de poniente que han caracterizado este último año.

Otro factor importante que repercute en los resultados finales de este proyecto es la comprobación de importantes colmataciones en las áreas inspeccionadas, llegando hasta el punto de no poder localizar restos de los que teníamos constancia por otras inmersiones realizadas en campañas arqueológicas desarrolladas hace tan soló cuatro años atrás, y en las que ya en su día era patente el aterramiento sufrido, reconociendo sólo parte de los restos de los que constaba el yacimiento. Este proceso geomorfológico parece tener relación directa con la alteración de factores que caracterizan la dinámica litoral de la Bahía de Cádiz. Los buceadores de la zona afirman, por otro lado, que este proceso de colmatación se ha agravado con las pérdidas de sedimentos que se producen en la cántara de los barcos que transportaban material procedente de dragados desde la zona de extracción (interior de la bahía) hasta la zona de vertido, ubicada en la parte externa de la misma. Este factor condicionará algunas intervenciones en las que será necesario actuar con medios mecánicos que permitan eliminar los limos acumulados, de manera inusual durante los últimos años.

A todo lo anteriormente expuesto se une también la necesidad de comenzar a definir, desde una perspectiva cultural, todos aquellos datos nuevos que se han ido y se van incorporando, además de la revisión de la documentación generada por antiguos proyectos que tenían este área dentro de su ámbito de actuación. La herramienta proporcionada por la Base de Datos Arqueos va a permitir la actualización de la información, en un formato ágil de consulta y revisión. Por otro lado, hacía falta que se diesen dos condicionantes para realizar un estudio en profundidad en el tema de la arqueología subacuática en los bajos de Cádiz; por una parte el darle continuidad a las intervenciones, dejando de producirse éstas en forma de campañas puntuales en el tiempo y en el espacio, y por otra desarrollar los estudios que se deriven de las intervenciones, intentando buscar aquellos datos tendentes a identificar conjuntos, y no quedarnos en la espectacularidad de piezas descontextualizadas que muestran sólo la parte artística de los objetos ( Foto 7).

Como conclusión final apuntar que estimamos que se ha iniciado el proceso adecuado para abordar un estudio de estas características, ya que en este proyecto convergen una serie de circunstancias y se cumplen unos determinados requisitos que pueden llegar a convertirlo en un modelo de actuación para futuras intervenciones arqueológicas. 